\title{
COVID-19 and the school response: Looking back to learn what we can do better
}

On 9 March 2020, Minister of Basic Education Dr Angie Motshekga stated in a media briefing that schools should not make their own decisions in response to concerns about learners or staff with possible coronavirus, or schools closures. She noted that the Department of Basic Education (DBE)'s actions should be led by the Department of Health when managing the impending crisis. ${ }^{[1]}$ At the time, South Africa (SA) had already had a 6-week head start to prepare an adequate public health response to the coronavirus. During the lead-up to the first report of an individual confirmed with COVID19 on 5 March 2020, the Minister of Health informed the SA public that the country was well prepared to manage the threat. In support of his statements, the National Institute for Communicable Diseases (NICD) was exemplary in establishing laboratory test kits and providing up-to-date information to healthcare workers and the population at large, while the National Department of Health $(\mathrm{NDoH})$ prepared designated hospitals to manage the anticipated caseload. However, we would argue that the response with regard to schools was woefully lacking. The absence of visible leadership by the $\mathrm{NDoH}$ is sadly reflective of our country's ongoing focus on curative care rather than being inclusive of prevention and health promotion, the key tenets of primary healthcare and a health systems-wide approach.

Schools provide an excellent opportunity to reach children and adolescents from all socioeconomic backgrounds, and school health services constitute a promising platform to improve health equity by increasing coverage of needed health services in the most disadvantaged communities. ${ }^{[2]}$ However, the COVID-19 pandemic has raised very difficult questions about how to place the health of our children at the centre of our response, and what kind of school health system will best protect children and their families in the context of community spread.

Drawing on lessons learnt from the 2013/14 Ebola outbreak, a resilient health system is one with the capacity to prepare for and respond to emergencies such as disease outbreaks, maintain core functions during emergencies, and learn from the emergency and reorganise as appropriate ${ }^{[3]}$ One of the essential features of a resilient health system is integration, where diverse actors from inside and outside the health sector, from government and non-government organisations and civil society, work together in a co-ordinated manner with a designated focal point for such co-ordination. ${ }^{[3,4]}$ Integration is best achieved with pre-existing policies and co-operative agreements. ${ }^{[3]}$ The Integrated School Health Policy, outlined in the National Health Insurance White Paper ${ }^{[5]}$ conceptualises SA's school health system as embodying an intersectoral approach, with close collaboration between the departments of Basic Education, Health, and Social Development.

The COVID-19 pandemic has foregrounded the importance of intersectoral collaboration when developing a response for the education sector. No national or provincial guidelines, protocols, or instructions on how to immediately manage a suspected case or contact in the school environment - regardless of the nature of the communicable disease - were available prior to 11 March 2020, when the NICD published guidelines for schools, after several schools had already been affected and closed due to so-called 'viral contamination' and 'deep cleaning. Public health principles dictate that there should be a systemic and co-ordinated response to anticipating, recognising, evaluating and controlling a health threat. In an uncertain environment, having a protocol prepared in advance would have provided schools with the confidence that they had carried out their duty of care to an ill child as effectively as possible, while simultaneously protecting the health of others in their care and those coming onto their school grounds.

All schools were closed on 18 March 2020, and the country entered lockdown 10 days later. School closure was informed by knowledge of the behaviour of several other respiratory viruses, including influenza, which spread rapidly in the school environment when attack rates are higher in children than in adults. ${ }^{[6]}$ For SARS-CoV-2, there is growing but limited epidemiological evidence to suggest that children are not the main source of infections, ${ }^{[7]}$ although modelling data of the effects of school closures are contradictory. ${ }^{[8,9]}$ Perhaps the most compelling data for a reduced transmission risk in schools come from an Australian tracing study in 15 schools indicating that none of 735 students and 128 staff contracted COVID-19 from 9 child and 9 adult initial school cases, despite close contact. ${ }^{[10]}$ A robust living systematic review by ourselves in partnership with the University of Edinburgh, which will synthesise the results from eligible studies following appropriate study quality appraisal, is underway. ${ }^{[11]}$ The review will aim to define the level of certainty of the evidence more clearly as new data emerge from countries that elect to return to school.

Now, as we are poised to return to school in early June, more than ever there is a need for co-ordinated intersectoral collaboration between the $\mathrm{NDoH}$ and the $\mathrm{DBE}$ to address teachers' concerns and parents' fears regarding children's and their own health. Directives for opening schools and necessary mitigation measures arrived late from the DBE on 29 May 2020, with the ongoing dispute between teacher unions and several provincial DBEs widely reported in the media. Earlier, on 19 May 2020, the Minister of Basic Education presented her decisions to the public alone, without the Minister of Health by her side to field the more challenging health questions. This was a missed opportunity to present a unified approach to the public and to educators. Many professional associations have attempted to plug the gaping operational hole, including guidance from the College of Public Health Medicine COVID-19 Evidence-based Task Team, published on 30 April 2020, ${ }^{[12]}$ and a recent statement from the South African Paediatric Association. ${ }^{[13]}$ Education advocacy organisations, such as the Equal Education Law Centre, continue to interrogate the details of the departmental directives. ${ }^{[14]} \mathrm{A}$ more co-ordinated, intersectoral response may have avoided duplication of efforts.

Now - and beyond COVID-19 - we require a national intersectoral approach including Health, Basic Education, and Social Development, partnered with other relevant departments such as Water and Sanitation and Transport, parent bodies, teacher unions, learner representation, and non-government organisations, that pays due attention to the opportunities for a co-ordinated and effective public health response in the school setting. In accordance with the World Health Organization's Global School Health Initiative, ${ }^{[15]}$ a national body responsible for school health and schools policy - when viewed through the COVID-19 lens - would have:

- prepared and developed clear guidance and protocols to manage suspected and confirmed cases and contacts, in advance of COVID-19 arriving in SA 
- prepared, collated and kept up-to-date systematic reviews of evidence regarding incidence in children and transmission from children to other children and to adults in the school environment

- provided clear guidance to schools regarding preparation for measures such as physical distancing and hygiene towards opening in a timely manner

- developed user-friendly health promotion materials and communication plans for schools

- developed a plan to continuously evaluate the implementation and impact of schools opening. A representative sample of schools across the country would be targeted for: (i) epidemiological surveys to evaluate incidence and transmission risks (including viral genotyping studies); (ii) evaluation of the feasibility of implementation of mitigation measures; (iii) measurement of educational outcomes; and (iv) student, parent and teacher knowledge, attitudes and behaviours.

In response, a comprehensive school health service based at school level would have been designated to:

- implement protocols to assist in managing cases and contacts

- assess and refine health promotion materials for local applicability and distribution

- implement communication plans through multimedia to school stakeholders

- advise schools regarding practical implementation of the mitigation measures (e.g. how to achieve adequate physical distancing)

- assist in the continuous evaluation of the implementation and impact of schools opening.

The responsibility for the above is not clear and will require further thought and consultation. The proposed National Public Health Institute Bill is silent on school health. ${ }^{[16]}$ We would argue that the NICD may not be the most appropriate body to deliver policy and protocols for schools, given their urgent need to focus on surveillance and laboratory preparedness. Health emergencies and disease outbreaks present the opportunity to systematically strengthen health systems during the outbreak response when there is heightened attention and increased resources. ${ }^{[17]}$ It is time to think about a national co-ordinated platform for the school health system to place the health of our children at the heart of the future of South Africa.

Acknowledgements. We thank Prof. Leslie London and Dr Jim Te Water Naude for their helpful comments.

Conflicts of interest. NS is a current member of the World Health Organization Guidelines Development Group on Comprehensive, Multicomponent School Health Services.

\section{Nandi Siegfried}

Independent Public Health Medicine Specialist; Chief Specialist Scientist, South African Medical Research Council, Cape Town, South Africa; and Honorary Associate Professor, Department of Psychiatry and Mental Health, University of Cape Town, South Africa nandi.siegfried@gmail.com

\section{Cathy Mathews}

Director and Chief Specialist Scientist, Health Systems Research Unit, South African Medical Research Council, Cape Town, South Africa; and Honorary Associate Professor, School of Public Health and Family Medicine and Department of Psychiatry and Mental Health, University of Cape Town, South Africa

1. ENCA. Minister Angie Motshekga media briefing. 9 March 2020. https://www.enca.com/news/ livestream-minister-angie-motshekga-briefs-media (accessed 31 May 2020).

2. Knopf JA, Finnie RK, Peng Y, et al. School-based health centers to advance health equity: A community guide systematic review. Am J Prev Med 2016;51(1):114-126. https://doi.org/10.1016/j. amepre.2016.01.009

3. Kruk ME, Myers M, Varpilah ST, Dahn BT. What is a resilient health system? Lessons from Ebola Lancet 2015;385(9980):1910-1912. https://doi.org/10.1016/S0140-6736(15)60755-3

4. Nuzzo JB, Meyer D, Snyder M, et al. What makes health systems resilient against infectious disease outbreaks and natural hazards? Results from a scoping review. BMC Public Health 2019;19(1):1310, https://doi.org/10.1186/s12889-019-7707-z

5. National Department of Health, South Africa. National Health Insurance for South Africa (White Paper). https://www.gov.za/documents/national-health-insurance-10-dec-2015-0000 (accessed 31 May 2020).

6. Esposito S, Principi N. School closure during the coronavirus disease 2019 (COVID-19) pandemic: An effective intervention at the global level? JAMA Pediatr 2020 (epub 13 May 2020). https://doi. $\mathrm{org} / 10.1016 / \mathrm{S} 2352-4642(20) 30095-\mathrm{X}$

7. Royal College of Paediatrics and Child Health Research and Evidence Team. COVID-19 research summaries. https://www.rcpch.ac.uk/sites/default/files/generated-pdf/document/COVID-19---researchevidence-summaries.pdf (accessed 22 May 2020).

8. Zhang J, Litvinova M, Liang Y, et al. Changes in contact patterns shape the dynamics of the COVID-19 outbreak in China. Science 2020 (epub 29 April 2020). https://doi.org/10.1126/science.abb8001

9. Viner RM, Russell SJ, Croker H, et al. School closure and management practices during coronavirus outbreaks including COVID-19: A rapid systematic review. Lancet Child Adolesc Health 2020;4(5):397404. https://doi.org/10.1016/S2352-4642(20)30095-X

10. National Centre for Immunisation Research and Surveillance. COVID-19 in schools - the experience in NSW. 26 April 2020. http://ncirs.org.au/sites/default/files/2020-04/NCIRS\%20NSW\%20Schools\%20 COVID_Summary_FINAL\%20public_26\%20April\%202020.pdf (accessed 29 May 2020).

11. UNCOVER Network. What is the evidence for transmission of COVID-19 by children [or in schools]? 6 May 2020. https://www.ed.ac.uk/files/atoms/files/uncover_001-03_summary_-_children_
s. ansmission_of_sars-cov-2.pdf (accessed 22 May 2020.

12. College of Public Health Medicine.COVID-19 Evidence-based Task Team. Guidance Document 4: Reducing transmission of COVID-19 in the school environment: Informing public health recommendations. 30 April 2020. http://www.cmsa.co.za/force_download.aspx?documentid=6E5470433238363937396E547043\&nam $\mathrm{e}=\mathrm{CMSA}+\mathrm{CPHM}+$ Guidance+for+schools\&direct=y (accessed 1 June 2020).

13. Daily Maverick. Paediatricians support move to reopen schools. 31 May 2020. https://www.dailymaverick. co.za/article/2020-05-31-paediatricians-support-move-to-reopen-schools/ (accessed 31 May 2020).

14. Equal Education Law Centre. Joint Statement \#COVID19 - the Department of Basic Education must present clear and comprehensive plans to the public. 12 May 2020. https://eelawcentre.org.za/dbejs/ (accessed 1 June 2020).

15. World Health Organization. School and Youth Health, Global School Health Initiative. https://www.who. int/school_youth_health/gshi/en/ (accessed 1 June 2020).

16. Republic of South Africa. National Institute of Public Health of South Africa Bill [B 16B-2017]. https:// Republic of South Africa. National Institute of Public Health of South Africa Bill [B 16B-2017].
www.gov.za/sites/default/files/gcis_document/201808/b16b-2017a.pdf (accessed 1 June 2020).

17. Durski KN, Osterholm M, Majumdar SS, Nilles E, Bausch DG, Atun R. Shifting the paradigm: Using disease outbreaks to build resilient health systems. BMJ Glob Health 2020;5(5). https://doi.org/10.1136/ bmjgh-2020-002499

S Afr Med J 2020;110(8):727-728. https://doi.org/10.7196/SAMJ.2020.v110i8.14991 